\title{
Workplace bullying as sensemaking: An analysis of target and actor perspectives on initial hostile interactions
}

\author{
Katerina Zabrodska ${ }^{a^{*}}$, Constance Ellwood ${ }^{\mathrm{b}}$, Sara Zaeemdar ${ }^{\mathrm{c}}$ and Jiri Mudrak ${ }^{\mathrm{a}}$ \\ anstitute of Psychology, Academy of Sciences of the Czech Republic, Hybernska 8, Prague, Czech \\ Republic; ${ }^{\mathrm{b}}$ School of Languages and Linguistics, University of Melbourne, Melbourne, Australia; ${ }^{\mathrm{c}}$ Macquarie \\ Graduate School of Management, Sydney, Australia
}

\begin{abstract}
This study explores the micro-level processes sustaining hostile workplace behaviour at the level of interactions between targets and actors. Drawing on Weick's [1995. Sensemaking in Organizations. Thousand Oaks, CA: Sage] sensemaking theory, the study examined how targets and actors of workplace bullying made sense of each other's behaviours during first occasions of hostility. An analysis of collective biography stories of hostility in academia showed that targets experienced destabilisation of identity, positioned actors as arbiters of adequacy, and engaged in self-undermining. Actors' stories revealed not only moral condemnation of targets, failure to recognise the injury caused, but also precarious emotions, which could have subverted harmful behaviours. Based on these findings, the authors argue that understanding target and actor sensemaking is vital since it appears to contribute to power differentials between the parties from the very onset of hostility, thus allowing it to escalate. The implications for the development of a sensemaking approach to workplace bullying and organisational intervention are discussed.
\end{abstract}

Keywords: workplace bullying; workplace hostility; sensemaking; target; actor; collective biography; stories

\section{Introduction}

Over the past two decades, organisational researchers have recognised workplace bullying as a pressing problem of the modern workplace (Einarsen et al. 2011; Lutgen-Sandvik and Tracy 2012), which is defined by rapid changes, budget cuts, temporary contracts, growing insecurity and, consequently, a climate in which opportunities for negative workplace behaviours are increasing. The concept of workplace bullying is synonymous with terms such as mobbing and workplace harassment: gradual, cumulative mistreatment that includes 'personal attacks, social ostracism, and a multitude of other painful messages and hostile interactions' (Lutgen-Sandvik 2006, 406). Work- place bullying is also a communicative phenomenon (Lutgen-Sandvik and Tracy 2012), which involves repeated, hostile communication directed at one or more employees who have difficulty in defending themselves, leading to their victimisation (Einarsen et al. 2011) and, more often than not, exit from the workplace. Bullying at work is a destructive pattern of behaviour with negative effects at individual, workgroup and organisational levels (for a review, see Hoel et al. 2011; Hogh, Mikkelsen, and Hansen 2011).

Researchers have shown that academia is not immune from workplace bullying either. A number of studies have documented a relatively high incidence of bullying and other forms of workplace hostility in academic settings, particularly in universities (see e.g. McKay et al. 2008; Lampman et al. 2009; Keashly and Neuman 2010). Such hostile behaviours have been linked to specific structural and organisational features of higher education (Keashly and Neuman 2010) and to the neoliberalisation and corporatisation of universities (Thornton 2004; Twale and De Luca 2008). Defining features of neoliberal universities described as integral to workplace hostility include an ever- intensified workload, short-term contracts, funding pressures, excessive competitiveness and individualism, and power imbalances between administrators and lecturers (Zabrodska et al. 2011). Some scholars argue that negative workplace behaviours, such as excessive control, unrealistic work demands or aggressive communication, are gradually becoming accepted as necessary and commonplace in this corporatised climate (Twale and De Luca 2008).

Even though the number of studies into workplace bullying (both inside and outside academia) is rapidly growing, the extant empirical research has a number of deficiencies. One of the central weaknesses is that existing research continues to rely mostly on accounts from the targeted employees, while the perspectives of other participants involved, ${ }^{1}$ particularly the actors, have been neglected (Jenkins et al. 2011). The second, and related, weakness is the lack of attention paid to the interaction between and impact of the varied perspectives of participants. Even recent studies on actors of bullying (Jenkins et al. 2011; Bloch 2012) have been limited to the actor's perspective without taking into account how its interplay with the perspective of the target may contribute to the development of bullying. Thirdly, workplace-bullying research has been dominated by a functionalist paradigm grounded in positivist epistemology; an interpretative paradigm that explores the meanings given to bullying by its participants remains underdeveloped (Samnani 2013). Since hostile behaviours acquire meaning only through the interpretative work of the participants involved, such meanings are crucial for a deeper understanding of and intervention in workplace bullying.

Our aim in this paper is to address these limitations of existing research by exploring the interplay between target and actor accounts of hostile interactions in academia. In particular, we draw on Weick's theory of 
sensemaking (Weick 1995; Weick, Sutcliffe, and Obstfeld 2005) to examine how targets and actors of workplace bullying make sense of each other's behaviours during the first occasions of hostile interactions and how their sensemaking impacts on the perpetuation of harmful behaviours. We specifically focus on initial interactions between targets and actors. Such interactions are typically concealed, low-intensity negative acts (Hauge et al. 2011), which may be difficult to detect but can nevertheless escalate into more systematic bullying. By focusing on the onset of bullying, we aim to provide insight into the ways in which initial sensemaking by target and actor may impact their subsequent positioning and possibilities for action.

The data for this study were drawn from a collective biography project on bullying in academia (see also Zabrodska et al. 2011) in which seven researchers, including the four authors of this paper, examined their own experiences of bullying at work. As we explain below, collective biography is a novel qualitative methodology based on a collaborative analysis of researchers' autobiographical experiences with the phenomena under investigation (Davies and Gannon 2006). Participants in our project were researchers who labelled themselves as having experienced or engaged in workplace bullying in academic settings. Considering the difficulties with approaching enactors of bullying (Baillien et al. 2009; Glasø, Nielsen, and Einarsen 2009), the autobiographical nature of collective biography provides a unique opportunity to incorporate their often-excluded perspectives as unfolding through the narration and analysis of the researchers' own experiences.

\section{Workplace bullying: the conceptual framework}

Workplace bullying is a form of hostile workplace behaviour characterised by frequency, duration, escalation and a power imbalance between targets and actors (Einarsen et al. 2011; Hershcovis 2011). Of importance for the focus of our study on initial hostile acts is that bullying is 'a gradually evolving process in which the target in the early phases of the process is being exposed to subtle and often disguised forms of mis- treatment' (Hauge et al. 2011, 307). Thus, the early phases of bullying are characterised by low-intensity negative acts that may be difficult to distinguish from other, milder forms of workplace hostility, such as workplace incivility. Indeed, a number of researchers have recently called for an integration of the varied concepts of hostile workplace behaviours including the concepts of bullying and incivility - arguing that there is a considerable overlap between them (Aquino and Thau 2009; Hershcovis 2011; Keashly and Jagatic 2011). Specifically, several meta-analyses have indicated that, while these concepts differ conceptually, on an empirical level they tend to refer to identical behaviours (Hershcovis 2011). The differentiation between the varied forms of workplace hostility may therefore be challenging in empirical research, a point to which we return later.

Conceptually, what distinguishes workplace bullying from other forms of work- place hostility is the power imbalance between the parties involved (Hutchinson et al. 2010; Hershcovis 2011). Workplace bullying is generally defined by targets' lack of power and their consequent difficulty in defending themselves (Einarsen et al. 2011). This contrasts with other workplace hostility concepts (see Hershcovis 2011). For instance, workplace incivility is characterised by an 'incivility spiral' (Anderson and Pearson 1999) in which the original target is able to retaliate and thus may reverse positions with the actor. Within the dominant functionalist paradigm (Samnani 2013), the power imbalance has been conceptualised as being derived from the actor's organisational position (Keashly and Jagatic 2011), the actor's informal power (Hoel and Cooper 2000), the target's dependency on the actor (Einarsen et al. 2011) or target and actor personality traits (Aquino and Thau 2009). However, this approach has been limited to the concept of power as an individual property, which is inadequate to capture the complexity of power relations at work (Liefooghe and Mackenzie Davey 2001; Hutchinson et al. 2010).

In contrast, workplace-bullying studies drawing on social constructionist perspectives have provided an alternative understanding of power. The majority of these studies have been embedded in critical and postmodern paradigms (Samnani 2013) and, as such, have explored the ways in which power imbalances are intertwined with social structures and processes. For instance, a number of authors (e.g. Liefooghe and Mackenzie Davey 2001; Hutchinson et al. 2010; Zabrodska et al. 2011) have shown how bullying can be incited by organisational processes, thus linking the abuse of power to organisational discourses and practices rather than to individuals.

Others have examined how specific ways of constructing bullying can make employees vulnerable to hostility and reduce their capacity for resistance (Tracy, Lutgen-Sandvik, and Alberts 2006; Lutgen-Sandvik and McDermott 2011). Overall, studies drawing on social constructionism have demonstrated that power does not simply result from employees' organisational positions or personality, but is a dynamic force linked to the ways in which meaning is created, (re)produced and enacted in organisational settings.

\section{Workplace bullying as sensemaking}

In this paper, we extend this social constructionist focus by conducting an analysis of the ways in which targets and actors make sense of their initial interactions and the ways their sensemaking impacts their mutual positioning and the power dynamics between them. Rather than drawing on critical or postmodern perspectives, however, our study applies an interpretivist approach (Samnani 2013), which focuses on an in- depth exploration of the processes through which targets and actors give meaning to organisational reality. Sensemaking theory (Weick 1995; Weick et al. 2005) allows us to examine these processes. While the sensemaking perspective has been 
highly influential in organisational studies, it has been rarely applied in workplace-bullying research (Samnani, 2013; for exceptions, see Vickers 2007; Olson-Buchanan and Boswell 2008; Lutgen-Sandvik and McDermott 2011). We argue that this has been a crucial oversight. As we will show through our analysis, sensemaking offers an ideal theoretical framework for conceptualising a dynamic, processual and interpretivist approach to workplace bullying.

Sensemaking is concerned with how social actors make sense of situations of ambiguity and thus produce the reality they interpret (Weick 1995). This theoretical framework emphasises the interaction between action and interpretation (Weick et al. 2005), illuminating how individuals continuously interpret their environment and, through that process, enact and shape it. In this framework, organisational reality is not something people react to, but 'an ongoing accomplishment that takes form when people make retrospective sense of the situation in which they find themselves and their creations' (Weick 1995, 15). Within the context of debates about subjective/objective definitions of bullying (e.g. Einarsen et al. 2011), the emphasis on enactment of meaning implies that the sensemaking framework explicitly prioritises subjective perceptions of bullying over more objective descriptions. While sense- making is not based on accuracy and can often be biased (Weick 1995), it is con- sequential for organisational members' actions. It is these subjective processes of meaning-making that form the basis of organisational members' behaviour and, as such, generate the reality of bullying.

Sensemaking is most acutely experienced when expectations and ongoing activities are interrupted and an ambiguity of meaning requires new interpretations of the situation (Weick 1995). Given this link to situations of ambiguity, sensemaking has often been employed in relation to organisational change and crisis. However, on a more micro-level, workplace bullying is also a perfect case for sensemaking. Typically, targets of bullying are confronted with a lack of meaning or a multiplicity of meanings; bullying makes no sense (Lutgen-Sandvik 2008) or it can mean many different things (Lutgen-Sandvik and McDermott 2011). Thus, when faced with hostility at work, targets experience a profound confusion and a consequent need to make sense of their highly distressing condition. In such situations, sensemaking 'to some degree fixes events' meanings and causes so that part of the uncertainty and equivocality sur- rounding events is resolved' (Lutgen-Sandvik and McDermott 2011, 345).

As we have argued, only a few recent studies have explicitly used the concept of sensemaking to examine the various forms of workplace hostility. In their model of mistreatment at work, Olson-Buchanan and Boswell (2008) showed that sensemaking plays a crucial role in determining whether or not specific trigger situations are experienced and responded to as mistreatment. Vickers in her autoethnography of bullying used the concept of sensemaking to show that each story of bullying is fundamentally 'an act of sensemaking' $(2007,223)$. The most complex analysis so far, however, has been conducted by Lutgen-Sandvik and McDermott (2011) who examined how targets of supervisory bullying made sense of why they had been bullied and how they used 'framing vocabularies' to inform that sensemaking.

In developing their theoretical framework, Lutgen-Sandvik and McDermott (2011) identified three reasons why sensemaking is vital for understanding workplace bullying. First, sensemaking objectifies targets' experiences. The ways in which targets interpret their situation tend to define and fix the social reality of bullying and impact on subsequent responses to the situation. As the authors show, in many cases targets in their study constructed bullying as intractable, thus intensifying their sense of powerlessness. Second, the concept of sensemaking shows that targets' interpretations are never an individual process, but a process grounded in social discourses and shared framing vocabularies that may contribute to the target's perceived lack of influence over the situation (for instance, through externalising the causes of bullying as something beyond their control). Third, sensemaking provides an important space for transformation of the target's experiences; the identification of sensemaking themes which disadvantage the target can also be grounds for a more empowering sensemaking and resistance.

Drawing on the sensemaking framework, the current study specifically aimed to examine sensemaking employed by targets and actors during initial hostile interactions. The following research questions were posed:

\section{Research Question 1: How do targets of workplace bullying make sense of the first hostile acts targeted at them?}

Research Question 2: How do actors of workplace bullying make sense of their first hostile behaviours directed at other employees?

\section{Research Question 3: How does the interactive sensemaking between targets and actors impact on power relations between these participants?}

\section{Methodology}

\section{A collective biography}

In this study, we drew on the methodological practices of collective biography. Collective biography is an innovative methodology developed by Davies and Gannon $(2006,2009)$, which has been recently adopted in a 
widening range of interpretative, critical and postmodern studies (e.g. Dalzell et al. 2010; Gonick, Walsh, and Brown 2011; Zabrodska et al. 2011). In the tradition of memory-work (Onyx and Small 2001) and autoethnography (Ellis 2004), collective biography takes as data the researchers' own experiences. The main components of collective biography are research workshops in which a group of researchers come together for several days to work on a specific topic through remembering, narrating and writing about their own experiences on the topic (Davies and Gannon 2006). This collective process generates data in the form of short stories that provide rich and vivid descriptions of the researchers' lived experiences with the phenomenon under investigation. Stories are then collaboratively analysed, often with the aim of using these experiences to develop new theoretical understandings of the topic.

Collective biography belongs, among alternative approaches, to social research that questions the positivist tradition, the objectivity of science, the neutrality of the researcher (Gonick, Walsh, and Brown 2011) and the liberal humanist notion of individual (Davies and Gannon 2009). Consequently, this methodology differs from more traditional methods in several important aspects. First, rather than being conceptualised as autonomous individuals, researchers' selves are viewed as being produced through discourse and processes of subjectification (Foucault 1980). The aim is thus not to generate knowledge about individuals but to examine shared processes of meaning-making through which individuals become specific kinds of subjects, such as moral or immoral beings (Davies and Gannon 2006). Second, research findings are conceptualised as being co-constituted by researchers' interpretative skills and the discourses available to them, rather than solely by the data. Collective biography therefore resists strict methodological guidelines, such as coding. Instead, the emphasis is on intense engagement with the text and its collaborative analysis (Davies and Gannon 2006). Thirdly, as in organisational autoethnography (see Boyle and Parry 2007), by drawing on researchers' own experiences, collective biography closes the research subject/object gap. Stories told in the workshops are therefore treated not as fixed data about research objects that can be separated from researcher interpretation, but as flexible texts open for researchers' further elaboration and interpretation.

Collective biography allowed us to address the dearth of research - the 'black hole' (Rayner and Cooper 2003; Bloch 2012) - on the perspectives of actors. This lack of research results from the difficulty of finding participants willing to openly share their own negative behaviours (Baillien et al. 2009). Collective biography is ideal in such situations because researchers need not depend on others' willingness and capacity to communicate sensitive topics, but can probe their own experiences (Davies and Gannon

2006). Collective biography also involves several features that facilitate the exploration of sensitive issues. As was also the case in our project, the participants are typically recruited through networks of colleagues among whom exists a high level of trust. The workshops take place in informal environments, such as participants' private homes. Participants spend several intense days together discussing their experience with the research topic, as well as engaging in other activities, such as preparing food and engaging in informal conversations. These practices create an intimate environment, which allows for the exploration of self-threatening topics. In addition, the conception of the self-produced in discourse means that the participants' stories are treated as collective stories; i.e. stories describing processes in which we all have been 'collectively caught up' (Davies and Gannon $2006,11){ }^{2}$ Hence, the focus is not on the (in)adequacy of individual participants' behaviours, but on the deconstruction of shared processes. This, as we have experienced, further increases participants' capacity for selfdisclosure.

\section{Participants}

Given the focus of collective biography on an in-depth exploration of experience, research groups are typically small, with six or seven participants (Davies and Gannon 2006). Our diverse research group included scholars from Australia, the Czech Republic and Iran, who - prior to the workshop - had labelled themselves as having experienced or engaged in workplace bullying in academia. We were women and men in our 30-60's from five disciplinary backgrounds within the social sciences and humanities. The group was assembled through social networks and previous collaborations. All of us had prior knowledge of the methodological principles of collective biography and four of us had employed collective biography in previous projects (Davies and Gannon 2009; Zabrodska et al. 2011). We had all taught in either Australian or Czech universities, so it is these locations on which we focus in our stories. The political and cultural histories of these countries are of course quite different. The neoliberalisation of academia, which has been linked to bullying, is much more recent in the post-communist Czech Republic than in Australia and other Western democracies (Zabrodska and Kveton 2013). Nevertheless, rather than evoking difference (Gonick, Walsh, and Brown 2011), the processes of sensemaking provided a remarkable commonality.

\section{The process of collective biography}

To examine target and actor sensemaking, we followed the usual process of collective biography (for details, see Davies and Gannon 2006). Before the workshop, the participants were asked by the first author to think through their stories of bullying, and specifically the first occasions of hostility experienced or enacted. In order to 
stimulate our capacity for theory development, a selection of readings on workplace bullying was then circulated among the participants. The readings included classical texts on work- place-bullying research (e.g. Leymann $1990 ; 1996)$ as well as studies critically reflecting on the functionalist paradigm (e.g. Vickers 2007; Hutchinson et al. 2010). Next, the first author proposed trigger questions for our stories, which were then collectively modified by the group via joint e-mail discussions. To examine the target's perspective on initial hostile acts, we agreed on the question: Tell a story about your first experiences of being mistreated in an academic setting. To explore the actor's perspective, we chose the question: Tell a story about your first experience of having negative emotions towards someone in an academic setting and treating that person with disrespect. In the case of targets, the 'first' referred to the moments when the narrators first registered hostility from their co-workers. In the case of actors, the 'first' referred to the moments when the narrators first realised that they had behaved with hostility towards others. We used the wording 'mistreatment' rather than 'bullying' to reflect the relative subtlety of the first hostile acts, which the participants may not yet have (at the time of story) experienced as bullying.

We then met for three consecutive days at a research workshop to explore our own stories, dedicating one day to each question. ${ }^{3}$ We wrote the stories and read them to each other, and after listening to and questioning each other we rewrote and re-read our stories. What we sought, in the manner of collective biography, were specific

vivid moments rather than the long intricate stories that the topic of bullying often evokes (Vickers 2007). Since our aim was to explore initial acts of hostility, the moments described in the stories did not depict the whole development of our bullying experiences, as they are usually explored through interviews. Instead, they provided detailed descriptions of those moments in which we for the first time either experienced or engaged in hostile acts that later became more persistent and that we retrospectively labelled as the onset of bullying. In total, we generated 14 stories, of which half were written from the target perspective and half from the actor perspective.

As we have noted, due to a burgeoning of workplace hostility concepts, a decision about how to label specific forms of workplace mistreatment can be difficult, both for researchers and participants (Tracy, Lutgen-Sandvik, and Alberts 2006). This was also a challenge for our project, particularly because the distinction between the subtle hostility typical of the early stages of bullying and other lesser forms of mistreatment, such as workplace incivility, may be blurred. The decision to conceptualise our experience as bullying rather than any other type of workplace hostility was based on our subjective understanding as well as on correspondences between our experience and the defining features of workplace bullying (see e.g. Hershcovis 2011). Specifically, our experiences entailed negative, offensive and intimidating acts that occurred as patterns of hostility (rather than isolated acts), were oriented towards a specific employee (rather than being a form of generalised hostility), and involved a power imbalance between the target and instigator. At the same time, we recognise that naming specific acts as bullying is a subjective, interpretative process and that bullying occurs in diverse forms and intensities. Drawing on the concept of bullying 'degrees' (Lutgen-Sandvik, Tracy, and Alberts 2007), we located our experiences as low-degree bullying, which is subjectively damaging, but not deeply traumatising.

The last stage of the project involved a collaborative analysis of the stories generated at the workshop and writing of the final paper. As discussed above, collective biography does not strictly separate data from analysis. Rather, the final product of the research is what Davies and Gannon $(2006,14)$ call 'an analytical text', which takes the form of analytical comments about the stories written collectively by the research group. As with autoethnography, the transformation of the stories into the analytical text is a creative and holistic process (Chang 2008), rather than a set of predefined steps. The analysis involved a back-and-forth cycle of repeated readings of the stories generated at the workshop, a search for recurring patterns of meaning-making (themes) and collective interpretation of the identified themes. For instance, while re- reading our actors' stories, we observed that, before describing our own harmful acts, we, as narrators, tended to portray negative attributes of the targets. In further dis- cussing this issue, we were struck by how strongly we felt about the maintenance of social norms, which, we believed, the targets had transgressed. These discussions accentuated the link between our negative perceptions of the targets and what we under- stood as 'moral', which then led to the identification of the theme called 'moral condemnation of targets'. Hence, identification of the final themes emerged from the analysis of our stories, but was also shaped by the subsequent discussions, in which we further 'made sense' of our stories. After agreeing on the main themes, we began the collaborative process of writing the paper, in which we each took turns to redraft the paper (see Davies and Gannon 2006). In what follows, we explore the main themes identified in targets' stories and, then, in actors' stories.

\section{Findings and interpretation \\ The targets' stories \\ Destabilisation of identity}

In our first theme, the initial hostile interactions were characterised by a sudden rupture in organisational life and a destabilisation of our usual identity. Like other targets of workplace bullying (e.g. as reported by Lutgen-Sandvik 2008), we were all academics strongly invested in our identity as competent and virtuous employees. We experienced the first negative acts as an identity subversion whose unexpectedness left us confused and unable to effectively respond. This is illustrated in our first story. The narrator was newly employed in a university 
department in which most members were unsympathetic to her research paradigm. Over the course of time, the narrator became the subject of hostile communication, rumours and increasing social isolation (which finally led her to move to another university). The following story describes the moment when she first encountered hostility in her new job from a colleague who accused her of low standards of Bachelor's thesis supervision.

An email pops up from the mailbox sent by the department member who I have never met personally. I open the email and read: 'You have jeopardised the student's future by your irresponsible action. You have given him a false impression that his thesis was good, whereas in fact it did not even reach the standards of mediocre, barely passable work.' I feel a hot blush coming to my face. Is this actually an accusation of misconduct? For a short moment, a sense of disbelief prevails. How can it be? My behaviour has always been considered exemplary... I struggle with confusion and growing anxiety. Will there be any further consequences of this? Will others join in this accusation? I am aware of my quickening heart beat and the sweating palms. I cannot afford this situation to last. Hurriedly, I begin to write a response. I must explain that I certainly did not mean to jeopardise the student. And yes, I must admit that I might have been wrong. Perhaps even to offer an apology, even though I sense that there is more behind this accusation than the quality of the student's thesis.

While in the vulnerable position of being a new employee, the narrator was confronted with an accusation of poor work performance. The first part of the story draws attention to the unexpectedness of the allegation and conflict with the narrator's usual identity as an academic with 'exemplary' behaviour. The implication of misconduct contested this identity and threatened the narrator's belief that she was a worthy employee, inciting confusion and a strong emotional and bodily response. As other studies have indicated (e.g. Keashly and Neuman 2005), the unexpectedness of such hostile acts contributes considerably to their injuring effect and to the target's difficulties in responding. It also allows those engaging in the hostility to instantly gain power over the target by disrupting the target's sense of stability and of the predictability of organisational life (Lutgen-Sandvik 2008). As reflected in the second part of the story, the narrator's power deficit was further accentuated by her apprehension that the colleague's accusation might entail rejection by other colleagues and possible disciplinary action. Based on this sensemaking, the narrator chose to submit to the criticism by sending an apology letter to pre-empt any such action. However, this could be viewed as an undermining behaviour that further increased her power deficit and limited her possibilities for the defence of her performance.

\section{Positioning actors as arbiters of adequacy}

The second theme emerging from our target stories was the legitimisation of actors' behaviour. Specifically, during the first hostile acts, we interpreted actors' behaviours as representing institutional norms, or some more general code of conduct, to which we felt obliged to conform. Thus, based on our incapacity to conform to these standards, we perceived our own actions as individual failures. This was visible in our first story in which the narrator positioned her colleague as an arbiter of performance; a positioning that seemed to undermine the narrator's capacity for resistance. The following story, describing an incident of student-initiated bullying experienced by a young lecturer, also illustrates these dynamics. The narrator was newly employed at a university and had been assigned to teach a new Master's course, but without institutional support or adequate preparation time. The story describes her initial lecture when she first became the target of students' hostility.

I am beginning to feel the awkward looks, the whispers that are getting louder, and the secret laughs accompanied by nasty looks targeted at me. A few students are playing with their mobile phones; a couple have their Facebook pages open on their laptops. It is quite difficult to keep them silent or focused on the task. One of the girls says that what I am explaining is totally boring and they already know this stuff and I am wasting their time. I know this is nowhere close to the truth; I have marked their assignments and I know they are not familiar with these models and they have quite poor analytical skills. But I feel guilty: if only I could make it more interesting for them. I start to justify my methods and the fact that I am not in charge of the material being taught. The other girl starts talking to her friend saying, 'let it go, she doesn't get it'. And then the whole class is going: 'hooooo! wow!'

This story depicts a specific dynamics of 'contrapower' hostility (Lampman et al. 2009) in which the hostility was directed by students - normatively considered to be individuals with less power - against a faculty member. A power imbalance seemed to be created here through a 'mobbing effect', i.e. a situation in which a single individual finds it difficult to defend herself against a group (Einarsen et al. 2011). Further contributing to her power deficit, the young lecturer occupied a relatively low organisational position due to her status as a new employee. In addition, she had been assigned to teach the course without adequate institutional support. However, as indicated by her sense of guilt, the lecturer made sense of her own actions in terms of her personal failure and incapacity to engage the students, rather than in terms of institutional deficiencies or low organisational position. Although she 
felt that the students' criticism was not fully warranted, in justifying her lack of control over the lecture, the narrator effectively accepted the criticism and positioned herself as having less authority and the students as the arbiters of what counted as a proper job performance. This sensemaking appeared to work against an effective response to the students' hostility and contributed to her increasing power deficit. At the same time, the lecturer's submissive behaviour was used by the students as cues for their own sensemaking (presumably giving the students further evidence of the lecturer's inadequacy), which then provided grounds for escalation of their hostility.

Our other stories revealed similar themes. The narrator of the next story was an experienced professional newly employed at a university where she was reproached by a colleague for neglecting her professional duties. The narrator positioned her col- league as a representative of the institutional norms of her new workplace and, consequently, felt morally compromised by transgressing them. The following segment of the story reveals the moment of bodily shame following the alleged transgression and its incapacitating effect on the narrator:

I could feel my cheeks redden. I sat with my keys in my hand. All my work experiences drained from me. Got it wrong already. I felt a shame of being caught doing something wrong. I replayed the walk down and the conversation in my head. Really got it wrong. I shakily put the key in the ignition. Still replaying what she had said, I started to drive out, still quite shaken.

While the narrator eventually recovered herself, in the moment described, she took up a position of a faulty individual who 'got it wrong already', that is, of someone who has been found guilty of transgressing the institutional code of conduct. As in our other stories, the accusations of the transgression incited intensive selfdoubt in the narrator leading to self-undermining behaviours, a point taken up below.

\section{Self-undermining}

Research on workplace victimisation (e.g. Aquino and Lamertz 2004; Aquino and Thau 2009) indicates that targeted employees may have a higher tendency to communicate negative emotions, such as anxiety or fear, and to express submissive behaviour, both of which may increase their risk of being targeted. Our targets' stories also demonstrate this tendency. This is reflected in the theme we call 'self-undermining' in which we responded to first hostile acts in a way that weakened our own position and allowed further hostile behaviour in the future. Such self-undermining behaviour is illustrated by another excerpt from the student-initiated story from the young lecturer. In this excerpt, the lecturer is trying without success to manage the class.

The students are getting louder, talking in groups and sometimes laughing out loud while looking at me, wanting me to know I am the topic of their jokes. Then it happens: I am explaining a concept when I see them; two of the girls sitting there looking at me aggressively. They are giving me this challenging look as if they are just waiting for me to say something wrong. I stop talking and instead ask them, 'is there something wrong with what I am saying?' I feel my heart pumping too fast; I feel so hot; I feel tears building up and can hear my voice trembling but cannot help any of this: 'Is this exercise not helpful?'; my tone of voice begging for some sympathy.

The lecturer responded with anxiety to the students' hostility. Instead of asserting herself, she remained open to their accusations and derogatory remarks. In asking the students what was wrong with her performance, she took up a compromised position of someone who had done something wrong and strove to repair it. This response further subverted her formal power over the students and seemed to invite them to further attack. Her selfundermining behaviour was also accompanied by negative emotions of shame and anxiety, as reflected in the continuation of the lecturer's story.

The students are enjoying the live entertainment. I tell them I am trying to make the class interactive and need their cooperation. The same girl starts to say, 'can we move on to the next exercise? We want to leave early'. I start teaching again feeling ashamed of not being able to handle the situation, anxious of coming back to this class next week to see those faces again.

Shame is an emotion typical for targets of workplace hostility (Lewis 2004; Lutgen- Sandvik 2008). Like other targeted employees, the lecturer experienced shame both for being targeted and for being unable to stop the hostility (Lutgen-Sandvik 2008). Shame is highly damaging to individual identity, as it leads to feelings of humiliation and results in an inability to act effectively (Lewis 2004). Self-undermining emotions, such as shame and fear, further exacerbated both our perceived and enacted sense of power. 


\section{The actors' stories \\ Moral condemnation of the target}

The few recent studies on actor experiences indicate that actors of bullying tend to justify their behaviour as appropriate and reasonable (Jenkins et al. 2011; Bloch 2012). There is also other empirical evidence suggesting that workplace hostility in general can be legitimised by numerous means, for instance, as an unavoidable part of work routines (Hutchinson et al. 2010) or the need for managerial control (Simpson and Cohen 2004). Our analysis showed that, from the actor's perspective, justifications of hostility were based on moral condemnation of targets. Specifically, the first hostile acts were justified by reference to shared social norms and values, which the target had allegedly violated. Thus, the hostile acts were legitimised by what Bloch calls 'moral classification' in which targets are 'classified as professionally incompetent and as deviants in relation to the community of values' (2012, 165). Consequently, negative behaviours directed at targets were portrayed as appropriate acts, which sustained, rather than subverted, moral order. This justification is illustrated by the next story. The narrator was obliged to share her small university office with a part-time colleague, 'Beth' whose boxes of questionnaires cluttered the office. This created tension in the narrator who, over the course of time, began isolating and ostracising Beth, often sharing negative comments about Beth with other colleagues. The story describes the first encounter between the narrator and Beth after Beth had been forced by the narrator to remove the boxes.

I hear Beth entering the office. This is the first time I have seen her since the incident with the questionnaires. I have been slightly troubled by it but I managed to persuade myself that I did the right thing when I made her clear out all those boxes, which constantly blocked my way. After all, it was not acceptable for Beth to occupy such a huge part of the office when she does not work here as often as I do. It was not right for her to repeatedly disregard the opinions and needs of her colleagues. People should be considerate towards others and willing to make compromises. Beth obviously lacks these qualities. Still, I do not quite know how to behave towards her now when she is here. I have no clue how she feels. Did she take our conflict seriously? She says: 'Hi'. I am still thinking hard how to behave towards her. The seconds pass. The silence stretches. Shall I be friendly and forget the whole thing? Instead, I hear myself responding 'Hi' in an unusually icy voice. As if something forces me to treat her coldly. I do not ask how she is doing as I would normally do. Calmly, and without any further word, I turn to my computer and set to work. I feel strangely in control of the situation and of Beth and the feeling is not an unpleasant one.

As in our targets' stories, the organisational positions of the narrator and Beth were unequal. While the narrator was a full-time employee, Beth worked only part-time and was often absent from work, a position that may increase employee vulnerability to hostility due to their status as outsiders. This organisational power imbalance appeared to be further accentuated by the narrator's sensemaking. In attempting to make sense of a disturbance to her sense of comfort, the narrator interpreted Beth's behaviour as a violation of social norms - namely as Beth's inability to comply with the proper use of an office and her general 'lack' of social competencies. By contrast, the narrator positioned herself as a moral subject whose hostile actions were motivated by the inadequate behaviour of Beth. Thus, the narrator referred to Beth's alleged breaches of social norms to construct her own injurious acts as justified while constructing Beth's actions as an offence against social norms and thus as deserving punishment. In this way, the narrator took up a position of what Davies (2011) calls 'guardian of the moral order', as having the right to gate-keep what counts as acceptable behaviour at work. This particular sensemaking increased the narrator's perceived dominance over Beth and allowed her to continue to mistreat Beth despite her initial feelings of being 'slightly troubled' by her own actions.

This theme of moral condemnation of targets also resonated across our other stories. The narrators typically accounted for the harmful actions directed at their colleagues by an alleged violation of social norms, the alleged wrongdoings consisting mostly of minor offences related to 'proper' conduct, such as sending improper emails or wrongful use of university property. These offences were nonetheless sufficient for the actors to position themselves as having the right to punish the targets through hostility and exclusion.

\section{Failure to recognise the injury}

The second theme reflects the ways in which actors of hostile behaviour failed to recognise the full extent to which they caused harm to their targets. This illustrates the lack of empathy associated with actors of workplace hostility (Bloch 2012), which can be linked to the actors' disregard for the vulnerability of the target's position. The failure to recognise the injury caused to targets is illustrated by the continuation of the 'Beth story', which describes a moment in which the narrator, while realising that her isolating behaviour is inappropriate, reveals a lack of understanding of the target's position.

For an hour or so, the tapping on our keyboards is the only sound we hear. The silence in the office is getting more and more oppressive. I am becoming tense and unable to concentrate on my work. At this point, I am already painfully aware that I have been trying to punish Beth and that my behaviour is 
ridiculous. Without giving it any further thought, I look at her and say some banal remark that makes her respond with a cautious smile. The sense of relief brought by the break in the silence between us takes me by surprise. Yet, weeks later, my boss tells me that Beth feels excluded from the office.

As Bloch comments, processes of social exclusion are 'connected with disquiet and dis- comfort among all the persons involved', including the actors, due to the threat they pose to the 'urge for social bonding and connection' $(2012,168)$. In the excerpt, the narrator experienced the discomfort of her own hostile behaviour and therefore decided to express positive emotions towards Beth. She had failed, however, to under- stand the full impact of her actions, falsely assuming that her decision to resume talking to Beth repaired the situation. Thus, the brief moment in which the narrator became aware of the inappropriateness of her behaviour was not sufficient to dissuade her from continuing her hostile actions. It was only the boss's remark weeks later that allowed her to see that her actions were experienced by Beth as a form of exclusion that Beth had considered serious enough to divulge to their boss.

The difficulties of recognising the full impact of one's actions featured also in our next story in which the narrator had felt personally wounded by a colleague, 'Kerry', with whom she shared an office. Because of this, the narrator decided to give silent treatment to Kerry, for weeks ignoring her any attempts at conversation:

In the time Kerry and I have shared this office, I have noticed that she sometimes doesn't greet me when I come in to the room. Now I use this to justify not only not greeting her, but where possible, ignoring her entirely. I don't respond if she does greet me, and I am abrupt or busy when she tries to engage me. Over time I feel myself becoming increasingly cold and icy towards her while making a show of cheerful chat with others.

How many weeks later does our boss Andy call me into his office? Politely, ‘would you mind?' I go in and find Kerry there looking shrunken, red-eyed, pitiful. Crying uncontrollably. Andy is explaining that she has asked him to intervene in a situation she is finding intolerable. He is saying, 'She says you've been ignoring her, being uncivil. What is going on?' I am mortified. What have I done! I look at Kerry, so reduced, and feel horror at my behaviour.

As with our other actor stories, the narrator interpreted her colleague's behaviour as a violation of social norms and enacted this sensemaking through hostility and exclusion. As reflected in the first part of the story, while engaging in hostility, the narrator did not fully consider how her colleague was impacted. Instead, she focused on the colleague's current transgressions (which included no greeting when entering the office) and used them as justification for her own excluding behaviour. At the same time, the narrator's description of her own behaviour as 'cold and icy' suggests that she was, to some degree, aware of the hostile nature of her actions. Yet, similarly to the 'Beth story', the narrator did not recognise the full extent of the injury this behaviour caused to her colleague. Only after the colleague broke down and sought an intervention from their boss did the narrator recognise the full impact of her behaviour and feel horrified by its effects. This points to the importance of a third party intervention and explicit expression of pain by the targets in challenging the actors' sensemaking. For instance, Bloch (2012) finds that actors tend to justify bullying because targets did not appear to object to it, while Glas $\varnothing$, Nielsen, and Einarsen (2009) note that many actors seem to be unaware of the impact of their acts on targets. In this story, the boss' intervention and colleague's explicit expression of emotional injury disrupted the narrator's moral positioning and provided cues for different sensemaking - the one in which she herself was the norm violator ultimately causing the enacted hostility to cease.

\section{Precarious emotions}

Finally, the stories drew attention to the precariousness and vulnerability of the actor's position. Despite their justifications, narrators did not succeed in constructing their own acts as unequivocally moral and reasonable. They oscillated between competing emotions, feeling self-righteous at one moment in the event, doubtful or even remorseful at other moments, as in the 'Beth story' when the narrator for a short moment became aware that her behaviour was 'ridiculous'. In other stories, the actor broke down when confronted by the target's friends, was horrified by the effects of his or her actions, experienced a conflicted sense of Schadenfreude ${ }^{4}$ or sourced their acts to an experience of being emotionally wounded by the target. The following excerpt illustrates how the narrator, after publicly humiliating her colleague, oscillated between self- justification and self-doubt.

I stand up and leave knowing there were others in hearing distance. I am energised by my anger but feel the regret already building up inside as 'I've done it again'. I have shown public outrage and humiliated someone. Well he deserved it. But, did he really? 
The emotional vulnerability of the actor contrasts with the position of the actor as imagined by the target. It can be argued that by positioning the actors as the arbiters of adequacy, the targets construct the actor's position as stronger and as more invincible than it may be. Thus, it is conceivable that the position of the actor is more vulnerable, and thus potentially easier to challenge, than is imagined by the target.

\section{Discussion}

This study explored the ways in which targets and actors of workplace bullying con- structed the meanings of each other's actions during the first occasions of hostile inter- actions and the implications of these meaningmaking processes for participants' mutual positioning. The role of meaning construction in the development of workplace bullying has also been the main concern for other studies drawing on social constructionism (e.g. Liefooghe and Mackenzie Davey 2001, 2010; Hutchinson et al. 2010). However, stemming from critical and postmodern paradigms, these studies have typically analysed meaning construction on systemic and structural levels (Samnani 2013), exploring how societal and organisational discourses sustain and legitimise hostility. By contrast, drawing on Weick's (1995) sensemaking framework, we extended the focus on meaning construction to an interactional level, thus providing a more processual, dynamic perspective on the meaning-making involved in workplace hostility. Our stories made visible how both targets and actors continuously extracted cues from an ongoing flow of organisational events (e.g. a co-worker's use of office space), con- structed the meaning of these events (e.g. norm violation) and enacted that meaning back into the social reality (e.g. hostility as a legitimate response to norm violation). In this way, the present analysis provided insights into the process through which work- place hostility can develop in actual encounters between targets and actors, something that has so far remained notably underresearched (Keashly and Jagatic 2011).

Using collective biography, our analysis showed that sensemaking about initial hostile interactions was considerably different according to positioning as either target or actor. The first theme identified in targets' stories, destabilisation of identity, indicated that targets perceived first negative acts as deeply personal attacks on their professional identity. This theme can be linked to the concept of identity threat, which 'results from receiving negative information about the self' and 'can undermine a person's belief that he or she is socially valued' (Thau, Aquino, and Poortvliet 2007, 841). Interestingly, in responding to identity threat, targets in our stories did not appear to seek validation of the self, but to a large extent submitted to the negative information about themselves. Such submission appeared to increase their vulnerability and to reduce their capacity for resistance. The second theme, positioning actors as arbiters of adequacy, showed that, rather than attributing intent to harm to actors, targets positioned actors as setting or upholding standards of behaviour to which targets felt obliged to conform. Although such positioning may change after harmful acts have occurred for a longer period of time (MacIntosh et al. 2010), it can help to explain both the target's vulnerability at the onset of hostility and the difficulty of recognising and naming these acts as bullying, as reported by other studies (e.g. Lutgen-Sandvik 2008). Thirdly, as reflected in the theme of self-undermining, targets interpreted negative acts as partially caused by their own failures and, based upon this sensemaking, engaged in a variety of self-undermining behaviours, thus further increasing both their perceived and expressed powerlessness.

The first two themes identified in the actors' stories, namely, moral condemnation of the target and failure to recognise the injury, pointed to the important role of moral justification (Bloch 2012) and moral order in perpetrating workplace hostility. The link between hostility and moral order has been recently developed in analyses of school bullying where engaging in aggression was conceptualised as 'an excessive and mis- guided defence of a fixed and dominant normative moral order' (Davies 2011,278). Similarly, in our analysis, the hostile acts were made sense of and justified by their instigators as sustaining social norms. In this context, Bandura's model of moral disengagement (Bandura et al. 1996; Bandura 2002) is relevant for our findings. Moral disengagement refers to a process through which actors of hostility can disengage negative self-sanctions from their harmful acts by redefining these acts as moral (Bandura 2002). This can be achieved through a number of mechanisms. The first theme identified in our actors' stories - moral condemnation of target - corresponds to the mechanisms of moral justification in which targets are devalued and hostility is legitimised by varied 'worthy purposes' (Bandura et al. 1996, 364), such as the defence of normative order allegedly violated by the targets. The second theme - failure to recognise the injury - can be then linked to the mechanism of the disregard for consequences (Bandura 2002) in which actors of hostility minimise the detrimental impact of their actions on targets. These mechanisms featured prominently in our actors' stories and appear to have contributed to the continuation of the hostile treatment. At the same time, our analysis also made visible actors' precarious emotions and the potential challenges posed to an actor's self-justifications by either a target's explicit expression of injury or a third party intervention. Together with actors' partial awareness of the hostile nature of their actions identified in the analysis, their precarious emotions rep- resented moments of 'dissonance' that could potentially rupture the mechanisms of moral disengagement. In our stories, however, the dissonance was not sufficient to cause actors to refrain from hostility.

The attention to both target and actor sensemaking accentuates the relational and interactive aspects of workplace hostility, which have been left unexplored in studies limited to targets' sensemaking. Specifically, we 
would suggest that the themes identified in targets' and actors' sensemaking were complementary in the sense that they served to enhance power differentials between both parties. Targets' sensemaking appeared to heighten their sense of vulnerability and diminished their control over the situation while actors' sensemaking accentuated their feelings of control over the target. In this way, our analysis echoes findings (Tracy, Lutgen-Sandvik, and Alberts 2006; Lutgen-Sandvik and McDermott 2011) that targets' sensemaking may exacerbate their perceived lack of power and possibilities for agency. However, it also extends these findings by showing that actors' sensemaking can consolidate the actor's sense of power, further escalating the power disparity between the parties. The mutually reinforcing pattern was most apparent in relation to the positioning of the actors: both targets and actors positioned actors as those who set the standards of what counted as the proper behaviour or performance, thus intensifying the actors' power over the targets.

It should be noted here that our study is based on limited autobiographical data and that analysis of more extensive empirical material may yield other sensemaking processes, such as processes involving targets' explicit resistance (Lutgen-Sandvik 2006). Still, the marked contrast between target and actor sensemaking identified in our analysis suggests that future scholarship would benefit from developing an interactional approach to sensemaking. Such an approach would recognise that an event which is labelled as workplace bullying develops through an interplay between target and actor sensemaking (as well as the sensemaking of other involved participants) and through the ways in which this sensemaking is enacted back into the organisational reality (Weick et al. 2005). To develop such an interactive approach, future studies could look for inspiration to the relational model of workplace victimisation, proposed by Aquino and Lamertz (2004). This model is actually one of the few that conceptualises workplace hostility as a function of the relationship between target and actor (Keashly and Jagatic 2011) in which mutually reinforcing patterns of victimisation develop, something that has also emerged in our analysis. Aquino and Lamertz's model is grounded in positivist epistemology and, as such, examines this relational dynamic in terms of individual behaviours and personalities. The sensemaking approach to workplace bullying could, in contrast, explore reinforcing patterns in the form of meaning-making processes and study the impact of different sensemaking dynamics on the outcomes of bullying cases.

The capacity of sensemaking to increase the power imbalance between target and actor indicated by our analysis also suggests the need for future scholarship to explore in more depth the relationship between sensemaking and power. This relationship has remained markedly underinvestigated in sensemaking studies (Weick et al. 2005; Mills, Thurlow, and Mills 2010) and has only recently emerged in workplace- bullying research (see Lutgen-Sandvik and McDermott 2011). From a critical perspective, the prevalent focus of bullying research on organisational power as a source of power imbalance between target and actor is insufficient because power is not something which organisational actors simply 'have' (Lutgen-Sandvik 2006) as a result of their position. Rather, power is a dynamic relationship that must be negotiated and enacted in actual social encounters. Sensemaking seems to offer a fruitful theoretical framework for exploration of how meaning-making both reflects and further accentuates power differences linked to organisational hierarchy (Lutgen-Sandvik and McDermott 2011). For example, in all our targets' stories, the narrators were newly employed, a relatively low-status position which, in academia, increases the risk of being targeted (Zabrodska and Kveton 2013). It is plausible that the sensemaking themes identified in the targets' stories reflected the targets' relative lack of organisational power (e.g. in their tendency to accept others as arbiters of adequacy), while at the same time increasing that lack. This implies that future studies into workplace bullying should involve analysis of sensemaking in the context of organisational power, rather than only sensemaking per se. For example, researchers could take into consideration how employee sensemaking in cases of workplace bullying is influenced by access (or lack of it) to different forms of organisational power (e.g. formal, expert and social) and social privileges (e.g. based on gender or ethnicity).

Finally, future scholarship could also benefit from exploring sensemaking strategies used to legitimise workplace hostility and the relation between hostility and maintenance of normative order. Our analysis drew attention to the strategies of moral justification and disengagement used by the actors, which allowed them to constitute themselves as moral agents (Bandura 2002; Davies 2011). In this respect, our analysis echoes several recent studies, which argue that bullying can be framed as justified and legitimate by its actors (Hutchinson et al. 2010; Jenkins et al. 2011), particularly by linking it to the maintenance of organisational or social norms. As Bandura (2002) argues, few actors of hostility engage in harmful actions without being able to justify these actions, to themselves, as moral. This image of a 'moral/istic bully' differs considerably from the portrait of actors as immoral psychopaths reported by targets of bullying (Tracy, Lutgen-Sandvik, and Alberts 2006). Hence, future scholarship could examine in a more systematic fashion how organisational members, in making sense of workplace bullying, legitimise hostility and what culturally available discourses allow such legitimisation.

This study has direct implications for organisational intervention. Awareness of the identified sensemaking dynamics and the marked differences between target and actor sensemaking could help targeted employees and other organisational stakeholders (e.g. HR professionals) find more suitable responses to workplace hostility and to avoid its escalation. It is vital for targets, in particular, to recognise that their sensemaking can constrain their actions (Weick 1995) and that transforming disadvantageous sensemaking, such as that identified in our analysis, 
can allow for more productive outcomes. For employees engaging in hostility, on the other hand, awareness of the identified sense- making processes may allow them to recognise themselves as 'actors' and to become more reflexive about their conduct. The actor's tendency to justify hostility also indicates the importance of other organisational stakeholders, particularly managers and HR professionals, who may be in a position to intervene in and challenge the actor's sensemaking. Their active intervention is important given the vulnerability of targeted employees whose sensemaking tends to accentuate feelings of personal failure and diminished control of the situation (Tracy, Lutgen-Sandvik, and Alberts 2006). The effectiveness of an intervention could also be enhanced if it targeted the potential ruptures in actors' moral positioning posed by their precarious emotions as well as their inchoate awareness of the hostile nature of their acts. Practical experience suggests that some actors are capable of accepting feedback about the impact of their behaviour on targets and changing their behaviour accordingly (McCulloch 2010).

The effectiveness of bullying intervention depends on its occurring early in the relationship, something that is difficult to achieve. This is because early intervention requires stakeholders to be alert to even minor levels of hostility (Rayner and Lewis 2011). However, bullying typically stays hidden until it has escalated (Tracy, LutgenSandvik, and Alberts 2006) or, in academia, tends to be subtle and indirect (Keashly and Neuman 2010). Actors' expressed sensemaking, namely their 'legitimisation talk' (e.g. employees repeatedly engaging in justifications of negative treatment of their colleagues or accentuating colleagues' faults) could be used as subtle signs alerting organisational stakeholders to potential bullying. Additionally, the possibility that bullying can be incited by the actor's desire to punish others for their perceived norm violations (Aquino and Lamertz 2004) challenges the dominant perspective that workplace hostility disrupts social norms (Keashly and Jagatic 2011). It implies that, in preventing hostility, organisations should not only focus on strengthening employees' adherence to norms of civil behaviour, but simultaneously consider how workplace hostility may result from adherence to rigid interpretations of social and organisational norms.

\section{Limitations and future directions}

The study has several limitations, which, simultaneously, indicate areas for future research. Our findings are limited by the fact that the targets and actors in our stories were not counterparts in the same interactions. More insight could be gained from qualitative case studies of individual hostile incidents analysed from additional perspectives (e.g. bystanders and managers). Additionally, while collective biography is useful in providing detailed insight into the actors' experience, the generalisability of its findings is limited due to the small number of research participants and its specific focus on moments of participants' experiences. Although we see this method as legitimate for exploratory studies that allow the opening of a new field of enquiry, such as our study, future studies could employ different methods to uncover sensemaking processes (such as diaries, see Vickers 2007). Relatedly, we focused on the first moments of hostility and did not address its subsequent development. Further analysis is needed to examine the ways in which sensemaking processes and the related relational dynamics between targets and actors transform over time, and the ways in which the perpetuation of hostility can be diverted. Finally, in focusing on interactive sensemaking, we did not consider links between sensemaking and more global discourses, such as neoliberalism. While such links have as yet been rarely made, an adoption of critical sensemaking (Mills, Thurlow, and Mills 2010) could provide tools for such analysis.

\section{Conclusion}

This study extends previous research on the role of meaning construction in the development of workplace bullying by examining the sensemaking of targets and actors in initial hostile interactions. The study has indicated that target and actor sensemaking may differ considerably and, based on these differences, could play an important role in increasing power asymmetry between the parties, thus providing grounds for a subsequent escalation of hostility. In this way, the study made three important contributions. First, the study contributed to emergent research employing sensemaking to investigate workplace hostility (Vickers 2007; Olson-Buchanan and Boswell 2008; Lutgen-Sandvik and McDermott 2011). Given that understanding participants' sense- making is necessary for eliciting change (Samnani 2013), the development of such an approach is vital. Second, the unique focus of this study on both target and actor sensemaking opened up a space for future studies to explicitly explore sensemaking inter- actions - rather than sensemaking by one party - and to examine sensemaking dynamics in other organisational contexts and among a broader range of organisational actors. Thirdly, by drawing attention to moral justifications of hostility, the study contributed the recently emerging stream of work suggesting that workplace hostility is linked to the maintenance of social norms, rather than to their violation (Keashly and Jagatic 2011). Hence, the study provides an incentive to investigate how social norms and moral positioning can be used to perpetrate and legitimate hostility as well as strategies that could subvert such legitimisation.

\section{Acknowledgements}

This work was supported by The Czech Science Foundation [grant numbers P407/10/P146 and 14/02098S]. 


\section{Notes}

1. In this term, we include the target, the actor and bystanders. While our research examined the perspectives of all these participants, in this paper we focus only on target and actor accounts. We refer to instigators of hostility as 'actors' rather than 'perpetrators' in line with current conventions, as described, for instance, by LutgenSandvik and McDermott (2011). We also believe that the word 'actor' is better suited than 'perpetrator' to refer to the enactors of the relatively subtle forms of hostility examined here.

2. In practical terms, the focus on collectivity of experience is reflected in the collective 'we-ness' typical of collective biography papers and the absence of information about specific

authors of individual stories.

3. The third day was focused on the experience of bystanders which we do not discuss in this paper.

4. Pleasure deriving from the suffering of others.

\section{References}

Andersson, Lynne M., and Christine M. Pearson. 1999. "Tit for Tat? The Spiraling Effect of Incivility in the Workplace." Academy of Management Review 24 (3): 452-471.

Aquino, Karl, and Kai Lamertz. 2004. "A Relational Model of Workplace Victimization: Social Roles and Patterns of Victimization in Dyadic Relationship." Journal of Applied Psychology 89 (6): 1023-1034.

Aquino, Karl, and Stefan Thau, 2009. "Workplace Victimization: Aggression from the Target's Perspectives." Annual Review Psychology 60: 717-741.

Baillien, Elfi, Inge Neyens, Hans De Witte, and Nele De Cuyper. 2009. "A Qualitative Study on the Development of Workplace Bullying: Towards a Three Way Model.” Journal of Community \& Applied Social Psychology 19 (1): 1-16.

Bandura, Albert. 2002. "Selective moral Disengagement in the Exercise of Moral Agency." Journal of Moral Education 31 (2): 101-119.

Bandura, Albert, Claudio Barbaranelli, Gian Vittorio Caprara, and Concetta Pastorelli. 1996. "Mechanisms of Moral Disengagement in the Exercise of Moral Agency." Journal of Personality and Social Psychology 71 (2): 364-374.

Bloch, Charlotte. 2012. "How do Perpetrators Experience Bullying at the Workplace?" International Journal of Work, Organization and Emotion 5 (2): 159-177.

Boyle, Maree, and Ken Parry. 2007. "Telling the Whole Story: The Case for Organizational Autoethnography." Culture and Organization 13 (3): 185-190.

Chang, Heewon. 2008. Autoethnography as Method. Walnut Creek, CA: Left Coast Press.

Dalzell, Ann, Christine Bonsmann, Deborah Erskine, Maria Kefalogianni, Katie Keogh, and Kalliopi Maniorou. 2010. "Gliding Across the Liminal Space between Counselor and Counseling Researcher: Using Collective Biography Practices in the Teaching of Counseling Research Methodologies." Counseling and Psychotherapy Research 10 (2): 126-138.

Davies, Bronwyn. 2011. "Bullies as Guardians of the Moral Order or an Ethic of Truths?" Children \& Society 25 (4): 278-276.

Davies, Bronwyn, and Susanne Gannon, eds. 2006. Doing Collective Biography. Maidenhead: Open University Press.

Davies, Bronwyn, and Susanne Gannon, eds., with Constance Ellwood, Catherine Camden-Pratt, Katerina Zabrodska, and Peter Bansel. 2009. Pedagogical Encounters. New York: Peter Lang.

Einarsen, Ståle, Helge Hoel, Dieter Zapf, and Cary L. Cooper. 2011. "The Concept of Bullying and Harassment at Work: The European Tradition." In Bullying and Harassment in the Workplace. Developments in Theory, Research, and Practice, edited by Ståle Einarsen, Helge Hoel, Dieter Zapf, and Cary L. Cooper, 3-40. London: Taylor \& Francis.

Ellis, Caroline. 2004. The Ethnographic I: A Methodological Novel about Teaching and Doing Ethnography. Walnut Creek, CA: Altamira.

Foucault, Michel. 1980. Power/Knowledge: Selected Interviews and Other Writings, 1972-1977. New York: Pantheon Books.

Glasø, Lars, Morten Birkeland Nielsen, and Ståle Einarsen. 2009. "Interpersonal Problems Among Perpetrators and Targets of Workplace Bullying." Journal of Applied Social Psychology 39 (6): 1316-1333.

Gonick, Marnina, Susan Walsh, and Marion Brown. 2011. "Collective Biography and the Question of Difference." Qualitative Inquiry 17 (8): 741-749.

Hauge, Lars Johan, Ståle Einarsen, Stein Knardahl, Bjørn Lau, Guy Notelaers, and Anders Skogstad. 2011. "Leadership and Role Stressors as Departmental Level Predictors of Workplace Bullying." International Journal of Stress Management 18 (4): 305-323.

Hershcovis, M. Sandy. 2011. “'Incivility, Social Undermining, Bullying . . . Oh My!': A Call to Reconcile Constructs within Workplace Aggression Research.” Journal of Organizational Behavior 32 (3): 499-519. 
Hoel, Helge, and Cary L. Cooper. 2000. Destructive Conflict and Bullying at Work. Manchester: Manchester School of Management, UMIST.

Hoel, Helge, Michael J. Sheehan, Cary L. Cooper, and Ståle Einarsen. 2011. "Organizational Effects of Workplace Bullying." In Bullying and Harassment in the Workplace. Developments in Theory, Research, and Practice, edited by Ståle Einarsen, Helge Hoel, Dieter Zapf, and Cary L. Cooper, 129-148. London: Taylor \& Francis.

Hogh, Annie, Eva G. Mikkelsen, and Åse M. Hansen. 2011. "Individual Consequences of Workplace Bullying/Mobbing." In Bullying and Harassment in the Workplace. Developments in Theory, Research, and Practice, edited by Ståle Einarsen, Helge Hoel, Dieter Zapf, and Cary L. Cooper, 107-128. London: Taylor \& Francis.

Hutchinson, Marie, Margaret H. Vickers, Debra Jackson, and Lesley Wilkes. 2010. "Bullying as Circuits of Power." Administrative Theory \& Praxis 32 (1): 25-47.

Jenkins, Moira, Dieter Zapf, Helen Winefield, and Aspa Sarris. 2011. "Bullying Allegations from the Accused Bully's Perspective.” British Journal of Management 23 (4): 489-501.

Keashly, Loraleigh, and Karen Jagatic. 2011. "North American Perspectives on Hostile Behaviors and Bullying at Work." In Bullying and Harassment in the Workplace: Developments in Theory, Research, and Practice, edited by Ståle Einarsen, Helge Hoel, Dieter Zapf, and Cary L. Cooper, 41-74. London: Taylor \& Francis.

Keashly, Loraleigh, and Joel H. Neuman. 2005. "Bullying in the Workplace: Its Impact and Management." Employee Rights and Employment Policy Journal 8: 335-373.

Keashly, Loraleigh, and Joel H. Neuman. 2010. "Faculty Experiences with Bullying in Higher Education." Administrative Theory \& Praxis 32 (1): 48-70.

Lampman, Claudia, Alissa Phelps, Samantha Bancroft, and Melissa Beneke. 2009. "Contrapower Harassment in Academia: A Survey of Faculty Experience with Student Incivility, Bullying, and Sexual Attention.” Sex Roles 60 (5-6): 331-346.

Lewis, Duncan. 2004. "Bullying at Work: The Impact of Shame Among University and College Lecturers." British Journal of Guidance \& Counselling 32 (3): 281-299.

Leymann, Heinz. 1990. "Mobbing and Psychological Terror at Workplaces.” Violence and Victims 5 (2): 119 126.

Leymann, Heinz. 1996. "The Content and Development of Mobbing at Work." European Journal of Work and Organizational Psychology 5 (2): 165-184.

Liefooghe, Andreas, and Kate Mackenzie Davey. 2001. "Accounts of Workplace Bullying: The Role of the Organization.” European Journal of Work and Organizational Psychology 10 (4): 375-392.

Liefooghe, Andreas, and Kate Mackenzie Davey. 2010. "The Language and Organization of Bullying at Work." Administrative Theory \& Praxis 32 (1): 71-95.

Lutgen-Sandvik, Pamela. 2006. "Take This Job and...: Quitting and Other Forms of Resistance to Workplace Bullying." Communication Monographs 73 (4): 406-433.

Lutgen-Sandvik, Pamela. 2008. "Intensive Remedial Identity Work: Responses to Workplace Bullying Trauma and Stigmatization.” Organization 15 (1): 97-119.

Lutgen-Sandvik, Pamela, and Virginia McDermott. 2011. "Making Sense of Supervisory Bullying: Perceived Powerlessness, Empowered Possibilities.” Southern Communication Journal 76 (4): 342-368.

Lutgen-Sandvik, Pamela, and Sarah J. Tracy. 2012. "Answering Five Key Questions about Workplace Bullying: How Communication Scholarship Provides Thought Leadership for Transforming Abuse at Work." Management Communication Quarterly 26 (1): 3-47.

Lutgen-Sandvik, Pamela, Sarah J. Tracy, and Jess K. Alberts. 2007. "Burned by Bullying in the American Workplace: Prevalence, Perception, Degree and Impact.” Journal of Management Studies 44 (6): 837862.

MacIntosh, Judith, Judith Wuest, Marilyn Merritt Gray, and Sarah Aldous. 2010. "Effects of Workplace Bullying on How Women Work.” Western Journal of Nursing Research 32 (7): 910-931.

McCulloch, Barbara. 2010. "Dealing with Bullying Behaviours in the Workplace: What Works-A Practitioner's View." Journal of the International Ombudsman Association 3 (2): 39-51.

McKay, Ruth, Diane Huberman Arnold, Jae Fratzl, and Roland Thomas. 2008. "Workplace Bullying in Academe: A Canadian Study.” Employees Responsibilities and Rights Journal 20: 77-100.

Mills, Jean Helms, Amy Thurlow, and Albert J. Mills. 2010. "Making Sense of Sensemaking: The Critical Sensemaking Approach." Qualitative Research in Organizations and Management: An International Journal 5 (2): 182-195.

Olson-Buchanan, Julie B., and Wendy R. Boswell. 2008. “An Integrative Model of Experiencing and Responding to Mistreatment at Work." Academy of Management Review 33: 76-96.

Onyx, Jenny, and Jennie Small. 2001. "Memory-Work: The Method.” Qualitative Inquiry 7 (6): 773-786. 
Rayner, Charlotte, and Cary L. Cooper. 2003. “The Black Hole in 'Bullying at Work' Research.” International Journal of Management and Decision Making 4 (1): 47-64.

Rayner, Charlotte, and Duncan Lewis. 2011. "Managing Workplace Bullying: The Role of Policies.” In Bullying and Harassment in the Workplace: Developments in Theory, Research, and Practice, edited by Ståle Einarsen, Helge Hoel, Dieter Zapf, and Cary L. Cooper, 327-340. London: Taylor \& Francis.

Samnani, Al-Karim. 2013. "Embracing New Directions in Workplace Bullying Research. A Paradigmatic Approach." Journal of Management Inquiry 22 (1): 26-36.

Simpson, Ruth, and Claire Cohen. 2004. "Dangerous Work: The Gendered Nature of Bullying in the Context of Higher Education.” Gender, Work \& Organization 11 (2): 163-186.

Thau, Stefan, Karl Aquino, and Marijn Poortvliet. 2007. "Self-Defeating Behaviors in Organizations: The Relationship between Thwarted Belonging and Interpersonal Work Behaviors." Journal of Applied Psychology 92 (3): 840-847.

Thornton, Margaret. 2004. "Corrosive Leadership (or Bullying by Another Name): A Corollary of the Corporatised Academy.” Australian Journal of Labour Law 17 (2): 161-184.

Tracy, Sarah J., Pamela Lutgen-Sandvik, and Jess K. Alberts. 2006. "Nightmares, Demons, and Slaves: Exploring the Painful Metaphors of Workplace Bullying." Management Communication Quarterly 20 (2): 148185.

Twale, Darla Jean, and Barbara M. De Luca. 2008. Faculty Incivility. The Rise of the Academic Bully Culture and What to do about It. San Francisco, CA: Jossey-Bass. A Wiley Imprint.

Vickers, Margaret H. 2007. "Autoethnography as Sensemaking: A Story of Bullying." Culture and Organization 13 (3): 223-237.

Weick, Karl E. 1995. Sensemaking in Organizations. Thousand Oaks, CA: Sage.

Weick, Karl E., Kathleen M. Sutcliffe, and David Obstfeld. 2005. "Organizing and the Process of Sensemaking." Organization Science 16 (4): 409-421.

Zabrodska, Katerina, and Petr Kveton. 2013. "Prevalence and Forms of Workplace Bullying Among University Employees.” Employee Responsibilities and Rights Journal 25 (2): 98-108.

Zabrodska, Katerina, Sheridan Linnell, Cath Laws, and Bronwyn Davies. 2011. "Bullying as Intra-Active Process in Neoliberal Universities." Qualitative Inquiry 17 (8): 709-719. 